\title{
METAMODELING CHOICES FOR SEISMIC VULNERABILITY ASSESSMENT OF BRB-RETROFITTED LOW-DUCTILITY RC FRAMES
}

\author{
J. Ghosh ${ }^{1}$, F. Freddi ${ }^{2}$ \\ ${ }^{1}$ Department of Civil Engineering, Indian Institute of Technology Bombay, Mumbai, India \\ e-mail: jghosh@iitb.ac.in \\ ${ }^{2}$ Dept. of Civil, Environmental \& Geomatic Engineering, University College London, London, UK \\ e-mail: f.freddi@ucl.ac.uk
}

\begin{abstract}
Damage incurred in low-ductility reinforced concrete $(R C)$ buildings during recent earthquakes continues to underline their structural vulnerability under seismic shaking. Among the viable seismic retrofitting procedures, passive control systems such as buckling-restrained braces (BRBs) have emerged as an efficient strategy for structural damage mitigation through stable energy dissipation while providing additional strength and stiffness to low-ductility buildings. Although quantifying the beneficial effects of BRBs for vulnerability reduction through seismic fragility curves has been suitably investigated in literature, almost all such studies consider a deterministic description of the BRB device. This study illustrates a metamodeling framework rooted in statistical learning techniques for efficient seismic vulnerability assessment of BRB-retrofitted low-ductility $R C$ frames. The framework develops multidimensional probabilistic seismic demand models for response prediction of a case study retrofitted frames as a function of ground motion characteristics as well as the design parameters of the $B R B$ device. These demand models when compared against damage states capacity estimates subsequently yields vector-based seismic fragility functions that provide notable advantages over unidimensional fragility curves in terms of efficiency as well as generality. Additionally, uncertainties stemming from a multitude of sources can also be conveniently captured and propagated through the different stages of statistical model development. The proposed study aims to help researchers, stakeholders, and even device manufactures by providing a convenient tool for vulnerability evaluation of retrofitted structures with reasonable accuracy and enhanced efficiency of computation.
\end{abstract}

Keywords: Buckling-Restrained Braces, Reinforced Concrete Frames, Seismic Retrofit, Seismic Devices Uncertainty, Metamodeling. 


\section{INTRODUCTION}

Many recent earthquakes worldwide have continued to underline the substantial seismic vulnerability of existing reinforced concrete (RC) buildings (e.g., [1][2]) and the urgent need for reliable retrofit strategies to effectively increase their seismic safety and resilience.

Among the many retrofit strategies available, the use of passive control systems [3] such as buckling-restrained braces (BRBs) have emerged as an efficient strategy for structural damage mitigation through stable energy dissipation while providing additional strength and stiffness to low-ductility buildings (e.g., [4][5][7][6][8][9][10]). BRBs are a type of yielding device where a sleeve provides buckling resistance to an unbonded core that resists the axial stress. As buckling is prevented, the BRB's core can develop axial yielding in both tension as well as compression, with an almost symmetric hysteretic behaviour and the development of large and stable hysteretic loops, providing significant energy dissipation capacity [11].

The use of BRBs for seismic retrofitting has been widely investigated in the last few years, however, while the effect of some uncertain parameters, such as the ground motion record-torecord variability, is often investigated (e.g., [7][8][10]), only a deterministic description of the dampers' properties is usually considered.

The seismic reliability assessment of a structural system should consider all the uncertainties related to the seismic input, the geometry, the mechanical properties of the structure, as well as the dissipative devices contributing to the lateral load resisting system. Previous studies have shown that, in conventional structures, the effect of model parameter uncertainty is usually negligible with respect to the record-to-record variability [12]; however, this is not the case for structures equipped with dampers since their seismic response heavily depends on the properties of a few numbers of devices (e.g., [13][14][15][16]).

Dampers are produced by the manufacturer in order to meet the design values of some parameters and successively assessed by quality-control tests considering tolerance limits established by seismic and qualification codes (e.g., [17][18][19]). Codes worldwide provide varying tolerance limits for different types of devices, considering different device properties and the influence of multiple factors, such as, imperfections related to the manufacturing process, temperature variation, and aging. For example, the EN 15129 [17] requires the control of the devices' variation with respect to the nominal values introducing upper and lower limits of the devices' properties, defined by a tolerance. For 'displacement dependent devices', such as BRBs, the EN 15129 [17] requires performing qualification tests to show that the effective (i.e., secant) stiffness $K_{\text {eff,b}}$, and effective damping $\xi_{\text {eff, } b}$ evaluated in correspondence to the design displacement are in good agreement with the prescribed nominal design values. Tolerances are set to $\pm 15 \%$ to account for variation during the manufacturing process. These two control parameters $\left(K_{\text {eff, }, b}\right.$ and $\left.\xi_{\text {eff,b }}\right)$ exhaustively identify the primary characteristics of the device behaviour. Therefore, the code-based tolerance limits are also implicitly applied to other related parameters, such as the associated device forces and displacement capacity values. Similar recommendations exist within the ASCE/SEI 7-16 [18] and other seismic codes worldwide. In particular, the ASCE/SEI 7-16 [18] allows for tolerances that could go up to $\pm 20 \%$ from nominal design values and controlling the variation in terms of device's force $F_{b}$ and area of the hysteretic loop $E_{l o o p, b}$ measured during the tests wherein the latter parameter allows the control dissipation capacity variation of the devices.

In a recent study, Freddi et al. [16] investigated the influence of the BRBs' uncertainty related to tolerance limits used in device qualification control tests by considering a three-story three-bay RC moment-resisting frame (MRF) as case study. BRBs' uncertainty was implemented through a two-level factorial design strategy and Latin-Hypercube Sampling technique. Cloud analysis and probabilistic seismic demand models were used to develop fragility 
functions for the bare and retrofitted frame for four damage states while also accounting for the uncertainty in the property of BRBs. Risk estimates were successively evaluated for three casestudy regions. The results showed that, for the considered case-study structure, these uncertainties could lead to an increase of fragility up to $21 \%$ and a variation in seismic risk estimates up to $56 \%$. The obtained results underlined the impact of the BRBs' uncertainty and the need for appropriate safety coefficients for their design as functions of the tolerance limits adopted. Also, additional studies are required to investigate the influence of BRB device variability on different case study structures, considering different retrofit levels (i.e., different proportions of the base shear between the MRF and the BRBs) and the influence of different tolerance limits. This would require modelling a large number of case study structures and performing a large number of numerical analysis while considering the influence of all the above-mentioned parameters.

However, advanced probabilistic tools allow the study of the influence several parameters in a simplified and efficient way. In this direction, the present study investigates the use of a metamodeling framework rooted in statistical learning techniques for efficient seismic vulnerability assessment of BRB-retrofitted low-ductility RC frames accounting for different tolerance limits adopted during qualification tests of BRB devices. The framework develops multidimensional probabilistic seismic demand models for response prediction of a case study retrofitted frames as a function of: a) ground motion characteristics, and b) design parameters of the BRB device. These demand models when compared against damage states capacity estimates subsequently yields vector-based seismic fragility functions that provide notable advantages over unidimensional fragility curves in terms of efficiency as well as generality. The present study demonstrates the adequacy of such advanced probabilistic tool for vulnerability evaluation of retrofitted structures with reasonable accuracy and enhanced efficiency of computation and establishes a framework for the inclusion of uncertainties stemming from additional sources.

\section{CASE-STUDY RETROFITTED LOW-DUCTILITY FRAME}

\subsection{Frame Description}

The present study selects a benchmark three-story three-bays RC MRF, representative of non-seismically designed (low-ductility) low-rise RC buildings. This structure is representative of typical constructions designed before the introduction of modern seismic design codes in several areas of the mid-west of the USA, many countries in Europe, and several regions in Asia. Moreover, the availability of laboratory experimental test results from a 1:3 reduced scale model of the case-study frame [20], as well as frame-subassemblages [21], makes the selected reference structure as an ideal choice for this study. FE model validation against experimental results helps in gaining confidence in the numerical approach as well as predicted building response at both the global- and local-level.

Figure 1 shows the frame layout including the placement of the BRBs. The dissipative braces (BRBs) employed in RC MRFs are typically made by a series arrangement the BRB device and an elastic steel brace exhibiting adequate over-strength (see Figure 1). The case-study frame has an inter-story height of $3.66 \mathrm{~m}$, a total building height of $10.75 \mathrm{~m}$, and constant bay width of $5.49 \mathrm{~m}$. The building is designed for gravity loads only, without any seismic detailing provisions following the pre-seismic design rules of the ACI 318-89 [22]. Furthermore, negligible wind loads for low-rise structures, such as the case-study frame, leads to a complete lack of accounting for lateral loads in the frame design. The building columns are constant square sections of $300 \mathrm{~mm} \times 300 \mathrm{~mm}$, while beams dimensions are $230 \mathrm{~mm} \times 460 \mathrm{~mm}$ at each floor. The concrete compressive cube strength is $f_{c}=24 \mathrm{MPa}$, and the reinforcing bars are Grade 40 steel with a yield strength of $f_{y}=276 \mathrm{MPa}$. Further details on the case-study structure and 
reinforcement configurations within beams, columns, and beam-column joints can be found in Bracci et al. [20] and Aycardi et al. [21].

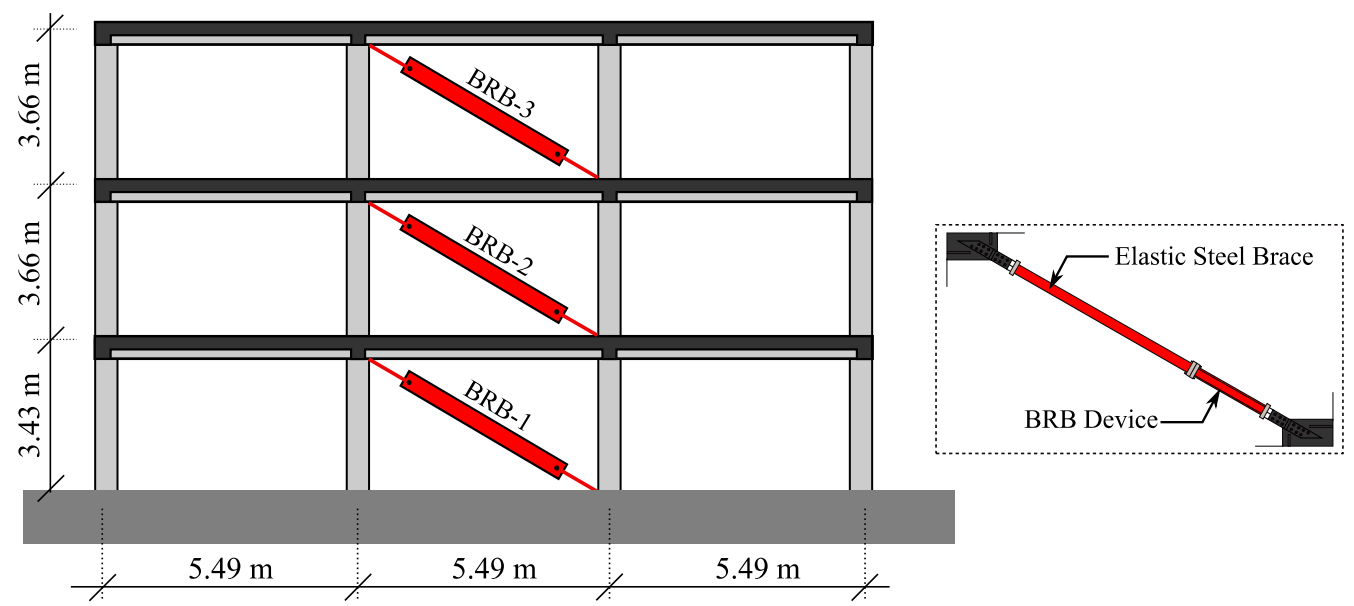

Figure 1: Case-study bare-frame layout (adapted from Bracci et al. [20]), placement and arrangement of BRBs.

The design of the BRBs is based on the methodology described in Freddi et al. [8]. The BRB design procedure is based on the displacement distribution of the first vibration mode and uses non-linear static analysis of the bare frame and a Single-Degree-of-Freedom (SDoF) simplification for the definition of some design parameters which are related to the retrofit objectives, such as the design displacement $\left(d_{u}\right)$; the target ductility of the dissipative braces $\left(\mu_{d}\right)$ and the base shear capacity of the dissipative system $\left(V_{d, 1}\right)$.

As shown in Figure 1, the retrofitting is performed by introducing the BRBs in the central bay at each story of the case-study frame. The base shear and the design displacement of the bare frame, defined based on the pushover analysis, are respectively $V_{f, 1}=180.72 \mathrm{kN}$ and $d_{u}=$ $0.308 \mathrm{~m}$ where $d_{u}$, is selected as the maximum lateral displacement capacity of the bare frame corresponding to the Complete Damage State.

In the present study, the retrofitted configuration investigated is the one where the base shear of the dissipative system $\left(V_{d, 1}\right)$ is selected equal to the base shear of the bare frame $\left(V_{f, 1}\right)$, or in other words, the strength proportion coefficient $\alpha=V_{d, 1} / V_{f, 1}$ is assumed equal to 1 [10], hence doubling the base shear resistance of the retrofitted frame. The ductility of the dissipative braces, i.e., dissipative device plus elastic brace $\left(\mu_{d}\right)$ is assumed equal to 15 . The design method provides properties such as strength $F_{d, i}$ and stiffness $K_{d, i}$ of the dissipative braces at each story. Assuming the ductility of the BRB devices $\left(\mu_{B R B}=20\right)$, the yielding resistance of the materials for BRB devices $\left(f_{y, B R B}=250 \mathrm{MPa}\right)$ and elastic braces $\left(f_{y, e b}=355 \mathrm{MPa}\right)$, and based on strength $F_{d, i}$, and stiffness $K_{d, i}$ of the dissipative braces, the properties of the components can be easily derived.

\subsection{Modelling Strategy}

The FE package OpenSees [23] is used to develop a state-of-the-art two-dimensional model of the case-study frame. The non-linear flexural hysteretic response of beams and columns is simulated using the 'beamWithHinges' element that consists of a central elastic element and two plastic hinge regions at the elements ends defined by fiber sections [24]. The effective flexural stiffness of the elastic portion of the element is evaluated by the ratio of the moment and the curvature corresponding to the yielding of the first rebar of the section. The plastic hinge lengths for both beams and columns are evaluated based on Panagiotakos and Fardis [25]. 
In these regions, fiber sections are defined that consider the spread of plasticity within unconfined (cover) concrete, confined (core) concrete, and layers of longitudinal reinforcement. While the core and cover concrete within the fiber sections are modelled using the non-linear degrading 'Concrete02' material model, the 'Hysteretic' material model is used to model the longitudinal reinforcements. For this material, the parameters controlling pinching, damage, and degraded unloading stiffness are calibrated such that close agreements are attained between the numerical and experimental results for model validation. The slab is modelled using unconfined concrete material model with an effective width equal to four times the beam's width, as recommended in the ACI 318-89 [22]. The rigid-floor diaphragm is modelled by assigning high axial stiffness to the beams. Gravity loads are distributed on the beams while masses are concentrated at the beam-column intersections.

'ZeroLength' shear and axial springs are introduced at the top of each column, by assigning them the 'LimitState' uniaxial material accounting for possible brittle failure mechanisms typical of low-ductility RC MRFs. Moreover, a two-node 'zeroLength' rotational joint spring and four rigid offsets are used to model the joint behaviour, including the influence of short embedment lengths of bottom reinforcements of beams within the beam-column joints as done in Jeon et al. [26]. In this model, beams and columns are continuous, while the joint model controls their relative rotation. The 'Pinching4' material model is used to define the beam-column joint response.

The dissipative braces are modelled by two elements in series representing respectively the BRB device and the elastic brace. The 'steelBRB' material model [11] is used to describes the hysteretic behaviour of the BRBs while capturing the kinematic and isotropic hardening, along with the tension-compression asymmetry that typically characterizes these devices.

The model both at component- and at global-level has been validated against the experimental results provided by Aycardi et al. [21] and Bracci et al. [20]. For the BRB devices a calibration has been conducted based on the results of the experimental qualification tests performed by a manufacturer. For additional details on the modelling and validation please refer to Freddi et al. [8][16][27].

\subsection{Uncertain Parameters}

The present paper investigates the influence of the uncertainty stemming from device-todevice variation by the definition of story- and system-level fragility curves. As previously discussed, for 'Displacement-dependent devices', such as BRBs, the EN 15129 [17] requires quality-control tests to show that the effective (secant) stiffness $K_{\text {eff, }, b}$, and effective damping $\xi_{\text {eff,b }}$ are in good agreement with the prescribed nominal design values and within prescribed tolerance limits. Alternatively, the ASCE/SEI 7-16 [18] controls the variation in terms of device's force $F_{b}$ and area of the hysteretic loop $E_{\text {loop, } b}$ measured during the tests. In both approaches, the two control parameters exhaustively identify the main characteristics of the device behaviour. Therefore, the code-based tolerance limits are implicitly applied to other related parameters.

In the present study, stiffness, force and dissipation capacity variations are numerically reflected within the model by accounting for variations in the area of the BRB devices $\left(A_{B R B}\right)$ while keeping the material yield strength $\left(f_{y, B R B}\right)$ as constant. Variation in the BRB device area $\left(A_{B R B}\right)$ has been chosen as opposed to the material yield strength $\left(f_{y, B R B}\right)$ as it induces the highest variation in the device response since alteration of the BRB area affects both stiffness, strength and the hysteretic energy dissipated. Device-to-device variation is assumed within the limits set by the codes (i.e., $\pm 15 \%$ in accordance with the EN 15129 [17] and ASCE/SEI 7-16 [18]) and applied independently among the devices at the different stories. The study considers different 
values of the tolerance limits assumed and investigates their influence in terms of fragility estimates.

\section{SURROGATE MODELLING AND PARAMETERIZED FRAGILITY DEVELOPMENT}

This section of the paper focuses on the development of parameterized seismic fragility functions for the retrofitted frame that are conditioned on the ground motion intensity measure (IM), and the BRB areas across the different stories. The following subsections outline the fragility development procedure that comprises of first constructing an experimental design matrix with uncertain model parameters, metamodel fitting to the response parameter, and eventual parameterized model development using logistic regression.

\subsection{Modelling design of experiments}

This study adopts a Latin Hypercube Design of experiments that initiates with discretizing the domain of each of the input variables $A_{B R B 1}, A_{B R B 2}$, and $A_{B R B 3}$ to $k$ intervals, where $k$ is the number of Latin Hypercube samples to be selected for each variable and eventually resulting in an experimental design matrix of $n \times k$. Following the discretization, the set of all possible Cartesian products of these discretized intervals constitutes the partitioning of the $n$-dimensional sample space to $k^{n}$ cells. Consequently, a set of $k$ cells are chosen of the possible $k^{n}$ cells such that the projection of the center of each cell on the respective axes of each parameter generates $k$ unique points. Consequently, choosing a random point within each selected cell generates a Latin Hypercube Design.

It is noted that the above procedure to generate sample points may still not guarantee an efficient exploration of the sample space. This study adopts a maximin based Latin Hypercube Design which selects design points after maximizing the minimum distance between the sample points ensuring that two points are not located too close together. For instance, if $l$ is a measure of distance (based on the $L 1$ or $L 2$ norm), and $\aleph$ is a $k$-point design, the smallest distance between any two points $A_{B R B i}$ and $A_{B R B j}$ may be given by:

$$
\min _{A_{B R B i}, A_{B R B j} \subset \ll, i \neq j} l\left(A_{B R B i}, A_{B R B j}\right)
$$

Consequently, a maximin distance design maximizes the minimum distance given in Equation (1) to generate another $k$-point design $\aleph_{M}$ such that the minimum distance between the points $A_{B R B i}$ and $A_{B R B j}$ now becomes:

$$
\min _{A_{B R B}, A_{B R B j} \subset \aleph_{M}, i \neq j} l\left(A_{B R B i}, A_{B R B j}\right)=\max _{\aleph \subset \Theta}\left[\min _{A_{B R B}, A_{B R B j} \subset \aleph, i \neq j} l\left(A_{B R B i}, A_{B R B j}\right)\right]
$$

where, $\Theta$ constitutes the $n$-dimensional design sample space. In addition to the maximin based Latin Hypercube design, this study also considers experimental design based on quasi-random sampling. A typical experimental design $D$ of size $k \times n$ generate by the Latin Hypercube Design can be represented as shown in Equation (3):

$$
D=\left[\begin{array}{ccc}
A_{B R B 1,1} & A_{B R B 2,1} & A_{B R B 3,1} \\
A_{B R B 1,2} & A_{B R B 2,2} & A_{B R B 3,2} \\
\vdots & \vdots & \vdots \\
A_{B R B 1, k} & A_{B R B 2, k} & A_{B R B 3, k}
\end{array}\right]
$$


where each row of the design matrix provides a unique combination of $\mathrm{BRB}$ areas within the tolerance limits. In addition to these parameters, a critical parameter of interest is the ground motion intensity $I M$. Due to the inherent randomness in ground motion time-histories, $I M$ is treated as an uncontrollable parameter in the experimental design. The uncertainty associated with ground motions is propagated in this study by pairing each row of the design matrix with a random time-history record and conducting nonlinear dynamic analysis of $k$-statistically similar but characteristically different retrofitted building samples. The peak interstory drift ratios for the overall frame are used next to fit multivariate probabilistic seismic demand models and fragility functions as described in the next step.

In the present study, the uncertainty affecting the seismic input in terms of variability in duration, frequency content, and other characteristics of the input expected to act on the system, is taken into account by considering the set of 240 natural records selected by Baker et al. [28].

\subsection{Metamodel fitting to storey level response}

Among the various metamodeling strategies, this study adopts the polynomial response surface models to approximate the maximum story and system level response as a function of the ground motion intensity measure and BRB areas. Polynomial response surface models were first developed by Box and Wilson [29] and have been widely adopted for predicting the response of complex engineering systems, such as buildings and bridges. The most widely used response surface models consist of low order polynomial functions. Simpson et al. [30] recommended that first order polynomials shall suffice for responses characterized by low curvatures: an assumption that is valid for the present case at hand. Consequently, first order response surface polynomials of the form shown in Equation (4) are adopted because of enhanced goodnessof-fit measures in comparison to first order polynomial models.

$$
\hat{y}=\beta_{0}+\beta_{I M}+\sum_{i=1}^{3} \beta_{i} A_{B R B i}
$$

In this equation, $\hat{y}$ represents the predicted value of the maximum interstory drift ratio (story level: $I D R_{\max , i}$ or system level: $I D R_{\max }$ ), and $\beta_{0}, \beta_{I M}$, and $\beta_{i}$ are the regression coefficients obtained using least square principles after fitting the response surface to the response data from nonlinear time history analyses of the retrofitted frame. Table 1 shows the regression coefficients for the polynomial response surface model for each of the three stories as well as the overall frame along with the $R^{2}$ goodness of fit measure indicative of the satisfactory response prediction at the story as well as system level.

\begin{tabular}{ccccc}
\hline & Story 1 & Story 2 & Story 3 & Whole Frame \\
\hline $\boldsymbol{\beta}_{\mathbf{0}}$ & 0.802 & 0.800 & 0.343 & 0.951 \\
$\boldsymbol{\beta}_{I M}$ & 1.023 & 0.978 & 0.877 & 1.005 \\
$\boldsymbol{\beta}_{\mathbf{1}}$ & -0.079 & 0.021 & 0.040 & -0.001 \\
$\boldsymbol{\beta}_{\mathbf{2}}$ & -0.039 & -0.099 & -0.013 & -0.091 \\
$\boldsymbol{\beta}_{\mathbf{3}}$ & 0.075 & -0.001 & -0.192 & 0.012 \\
$\boldsymbol{R}^{\mathbf{2}}$ & 0.831 & 0.891 & 0.895 & 0.860 \\
\hline
\end{tabular}

Table 1: Regression coefficients and $R^{2}$ estimates corresponding to the polynomial response surface model for the three stories and the overall frame.

The polynomial response surface model utilized in this study also aids in the identification of the critical variables other than $I M$ that most affect the interstory drift ratios. These are shown in Figure 2(a) through (b) using Pareto charts corresponding to maximum interstory drift ratios 
for the individual stories as well as for the overall frame. The left vertical axis of the Pareto charts represents the absolute $t$-statistic ratios for the parameters arranged in decreasing order of importance. This statistic is computed as the ratio between the parameter estimate and the corresponding standard error. The right vertical axis represents the cumulative sum of the absolute values of the $t$-ratio (in percentage) and elucidates the aggregated explanatory power of variables when jointly considered in succession. As Figure 2 reveals, while $I M$ emerges as the most critical variable across all stories, the story-level BRB areas affect the response of specific individual stories. In other words, among the three different BRB areas, $A_{B R B i}$ most affects the response of the $i^{\text {th }}$ story. This finding is intuitive and also aligns with the seismic design strategy used for the BRBs. For the overall frame, the maximum interstory drift ratio (IDR $\left.R_{\max }\right)$ is most dependent on $A_{B R B 2}$ at the second story as shown in Figure 2(d).

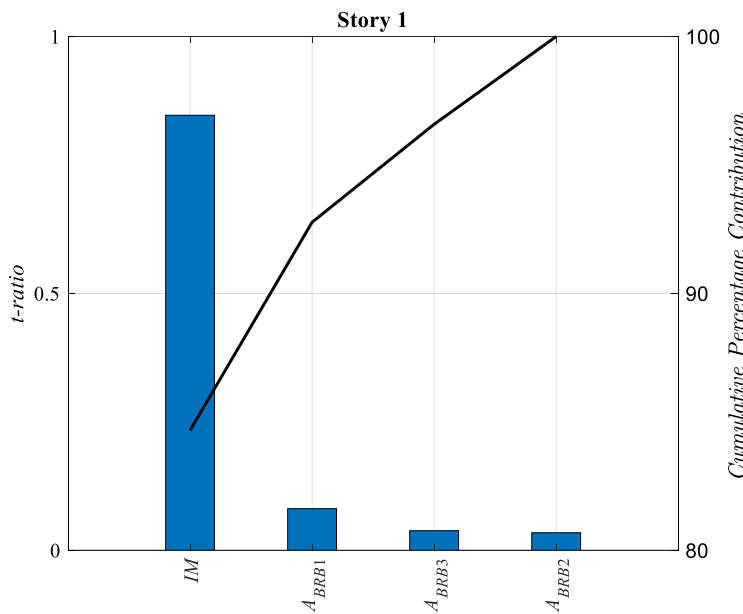

(a)

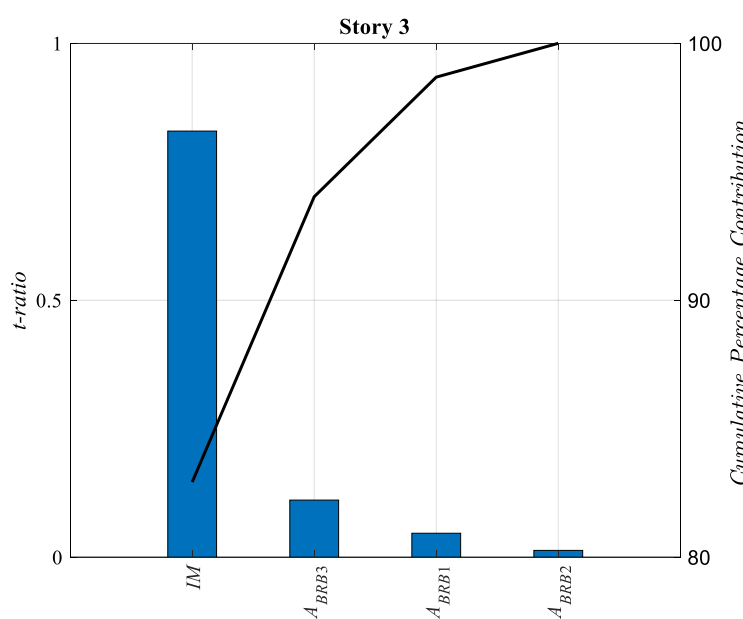

(c)

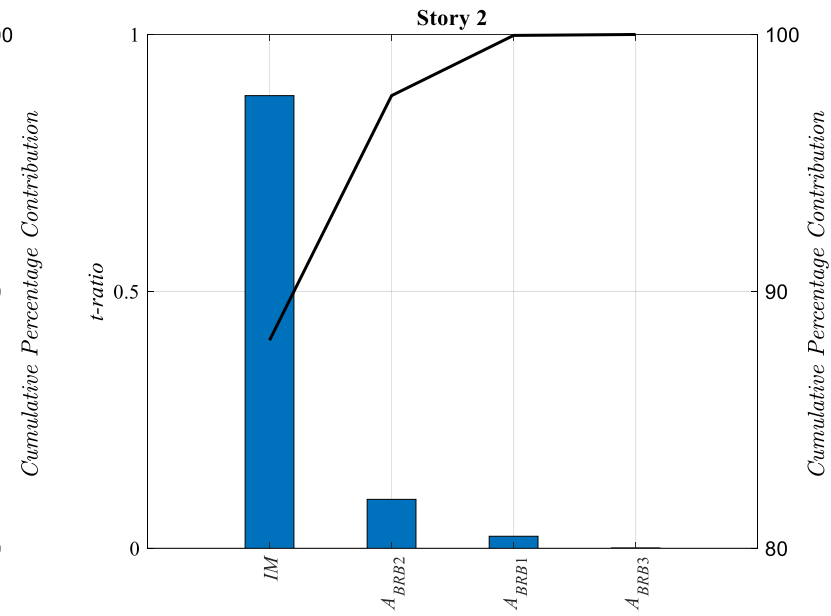

(b)

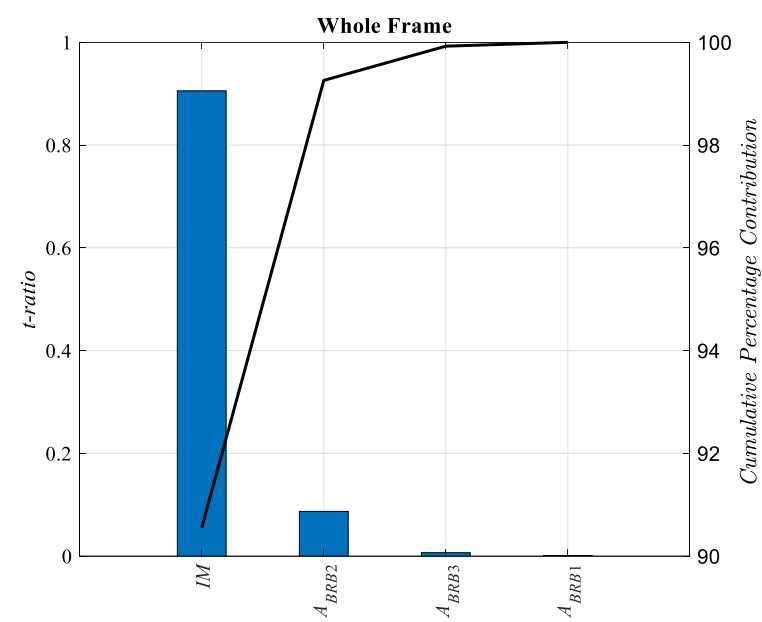

(d)

Figure 2: Pareto Charts depicting the contribution of the ground motion intensity measure and BRB areas on the maximum interstory drift ratios for a) Story 1, b) Story 2, c) Story 3, and d) Overall frame.

\subsection{Parameterized fragility function development}

The multidimensional story and system level seismic demand models developed in the previous section are utilized in this stage to develop parameterized seismic fragility functions after comparing with the capacity estimates. The capacity distributions for the individual stories as well as the overall frame are obtained using nonlinear static pushover analysis and are directly adopted from Freddi et al. [16]. Comparison between large number of seismic demand and 
capacity samples help generate binary survive-failure vectors. These binary vectors are then used to develop time-evolving seismic fragility functions by using the logistic regression approach. Note that other techniques such as naïve Bayes classifier, Probit model, Support vector machines, among others may be also utilized for fragility development. A brief description of the steps involved to develop fragility functions using logistic regression is provided herein [31][32]:

Step 1: For a particular building story or the overall frame, sample a large number $\left(N_{M C}\right)$ of demand estimates from the probabilistic seismic demand models of the maximum interstory drift ratios as elaborated in the previous step. These samples should ideally reflect substantially distinct combinations of the ground motion $I M$ and the BRB areas $\left(A_{B R B 1}, A_{B R B 2}\right.$, and $\left.A_{B R B 3}\right)$.

Step 2: Generate $N_{M C}$ capacity estimates from the capacity distribution of individual stories or the overall frame for the four considered damage states (i.e., Slight, Moderate, Extensive and Complete).

Step 3: Compare the demand estimates against the capacity samples and generate a binary vector $\{$ bin $\}$ consisting of 1's and 0 's, where, 1's represent a story or system-level failure (demand greater than capacity) and 0's represent a story or system-level survival (demand less than capacity).

Step 4: Conduct logistic regression using the binary survival-failure vector to determine the story or system-level failure probability for particular damage state $d s$ as:

$$
P f_{d s \mid I M, A_{B R B 1}, A_{B R B 2}, A_{B R B 3}}=\frac{e^{\theta_{0}+\theta_{I M} \ln (I M)+\sum_{i=1}^{3} \theta_{B R B i} A_{B R B i}}}{1+e^{\theta_{0}+\theta_{I M} \ln (I M)+\sum_{i=1}^{3} \theta_{B R B i} A_{B R B i}}}
$$

where, $\theta_{0}, \theta_{\mathrm{IM}}$, and $\theta_{B R B i}(i=1$ to 3$)$ are the story or system-level logistic regression coefficients for damage state $d s$. Table 2 below enlists the logistic regression coefficients that are utilized in the next section of the paper to derive seismic fragility curves for nominal BRB areas as well as quantify the effect of uncertainty on fragility estimates.

\begin{tabular}{ccccc}
\hline & Story 1 & Story 2 & Story 3 & Whole Frame \\
\hline $\boldsymbol{\theta}_{\mathbf{0}}$ & 8.140 & 2.071 & 0.405 & -3.013 \\
$\boldsymbol{\theta}_{\boldsymbol{I M}}$ & 6.102 & 6.014 & 6.739 & 11.942 \\
$\boldsymbol{\theta}_{\boldsymbol{B} \boldsymbol{R} \boldsymbol{B} \boldsymbol{i}}$ & -0.023 & -0.062 & -0.010 & 0.038 \\
$\boldsymbol{\theta}_{\boldsymbol{B R \boldsymbol { B }} \boldsymbol{i}}$ & -0.582 & -0.526 & -0.595 & -0.538 \\
$\boldsymbol{\theta}_{\boldsymbol{B R \boldsymbol { B }} \boldsymbol{i}}$ & 0.072 & 0.187 & 0.133 & 0.052 \\
\hline
\end{tabular}

Table 2: Logistic regression coefficients at story and system level for seismic fragility development.

\section{RESULTS AND DISCUSSIONS}

Unlike unidimensional seismic fragility functions as typically adopted for seismic vulnerability assessment of retrofitted frames, the parameterized fragility models developed in the earlier section offers several advantages. Firstly, for the nominal BRB areas, these fragility functions provide prompt estimates of individual story and system-level fragilities. For instance, Figure 3(a) depicts the individual story fragilities, as well for the whole frame corresponding to the design $\mathrm{BRB}$ areas. As expected, the fragility curve for the overall frame emerges 
predominantly more fragile than the individual stories. Additionally, among the different stories, the second story emerge as the most fragile and lies in close proximity to the system-level vulnerability curve. Secondly, without the need of additional computationally expensive finite element model runs, the parameterized fragility functions help investigate the influence of BRBs' property variation on retrofitted frame fragility. While Section 3 earlier showed that $A_{B R B 2}$ emerge as a critical parameter affecting the system-level frame response (IDR $\left.R_{\max }\right)$, Figure 3(b) depicts the variation of retrofitted frame fragility as a function of $A_{B R B 2}$ variation within $\pm 20 \%$ of design estimates for moderate damage state, while holding other BRB areas $\left(A_{B R B 1}\right.$ and $\left.A_{B R B 3}\right)$ constant at nominal values. As expected, the figure shows that higher $A_{B R B 2}$ areas tend to reduce the retrofitted frame fragility, however high BRB areas may not be optimal from the design perspective.

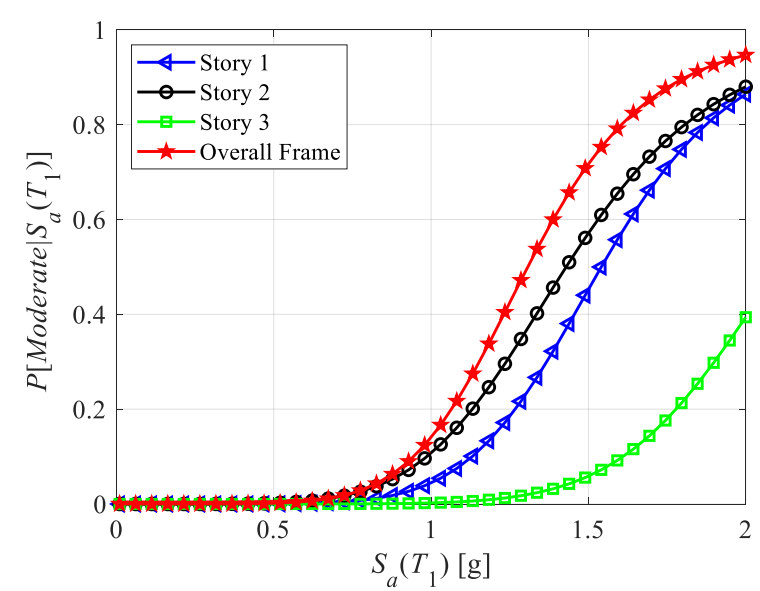

(a)

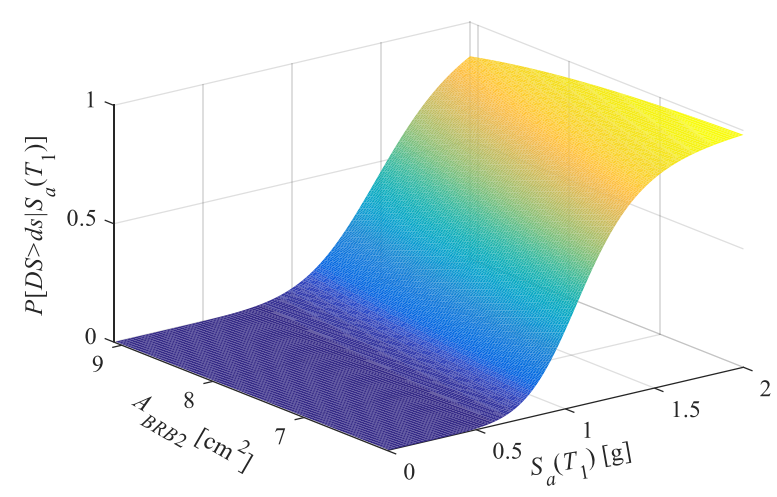

(b)

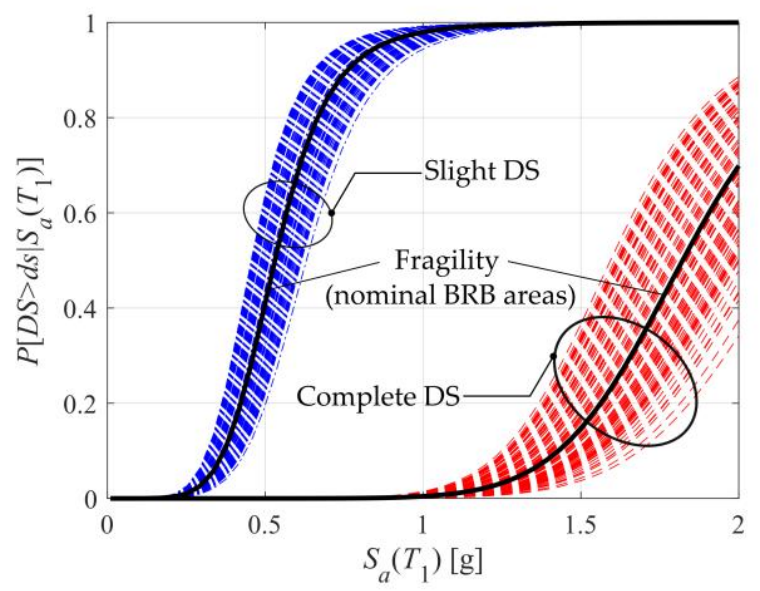

(c)

Figure 3: a) Seismic fragility curves for different stories as well as the retrofitted frame corresponding to the moderate damage state for nominal BRB areas, $b$ ) variation of retrofitted frame vulnerability with $\pm 20 \%$ variation of $A_{B R B 2}$, and c) fragility bands depicting the uncertainty in retrofitted frame fragility for the slight and complete damage states due to variations in $A_{B R B 1}, A_{B R B 2}$, and $A_{B R B 3}$ within $\pm 20 \%$ of design limits.

The parameterized seismic fragility functions also help estimate the bounds of fragility estimates corresponding to independent variation of the BRB areas across the three stories. Figure 3(c) shows the departures from the "mean" fragility estimates of the retrofitted frame for the slight and complete damage states due to variations in $A_{B R B 1}, A_{B R B 2}$, and $A_{B R B 3}$ within $\pm 20 \%$ of design estimates. These fragility bounds also underline the wide variability in retrofitted frame fragilities as a consequence of potential randomness in the BRB areas within the prescribed 
code limits. The upper and lower values of the median estimates are observed to range from $0.45 \mathrm{~g}$ to $0.62 \mathrm{~g}$ for the slight, $1.10 \mathrm{~g}$ to $1.51 \mathrm{~g}$ for moderate, $1.41 \mathrm{~g}$ to $1.91 \mathrm{~g}$ for extensive, and $1.53 \mathrm{~g}$ to $2.10 \mathrm{~g}$ for the complete damage states respectively.

\section{CONCLUSIONS}

Seismic fragility assessment of retrofitted structures typically uses conventional techniques for vulnerability evaluation that may often emerge as tedious in terms of computer run-time. Moreover, to ascertain the influence of parameter variation on building fragility one may need to resort to costly re-analysis under dynamic loads. This study focuses on a computationally efficient technique to assess the impact of variation in BRB device parameters on story level as well as overall retrofitted frame fragility.

To achieve the above objective, first an experimental design matrix is constructed that provides an optimum combination of BRB device areas (chosen as the parameter of interest) within $\pm 20 \%$ of nominal estimates while offering an efficient exploration of the sample space. Next through the results obtained from the nonlinear dynamic analysis of statistically different yet nominally identical frame models polynomial response relationships are developed between the story and system level maximum interstory drift ratios. Comparison of t-statistic ratios indicate than other than the ground motion intensity measure, individual story level BRB device areas emerge most critical for response prediction for that specific story. For the overall frame, the device area at the second story has the most controlling effect. Next, the developed polynomial demand models are compared with capacity estimates to derive parameterized fragility functions using logistic regression techniques. These functions offer significant advantages over traditional intensity-measure-only dependent fragility curves and helps prompt assessment of a) individual and overall frame fragility for nominal BRB area estimates, b) influence of parameter variation on story and system level fragility, and c) development of uncertainty bands to estimate the departures from "average" fragility estimates when variations in device areas are taken into consideration. For the retrofitted case-study frame, the upper and lower values of the median estimates are observed to range from $0.45 \mathrm{~g}$ to $0.62 \mathrm{~g}$ for the slight, $1.10 \mathrm{~g}$ to $1.51 \mathrm{~g}$ for moderate, $1.41 \mathrm{~g}$ to $1.91 \mathrm{~g}$ for extensive, and $1.53 \mathrm{~g}$ to $2.10 \mathrm{~g}$ for the complete damage states respectively.

Future work on this topic will investigate the influence of BRB device variability on different case study structures and will consider different retrofit levels (i.e., different proportions of the base shear between the MRF and the BRBs). In these cases, due to the variation of the structural vibration period, an alternative intensity measure needs to be evaluated, this representing one of the main challenges for the extension of the proposed methodology.

\section{REFERENCES}

[1] A. Rao, D. Dutta, P. Kalita, N. Ackerley, V. Silva, M. Raghunandan, J. Ghosh, S. Ghosh, S. Brzev, K. Dasgupta, Probabilistic seismic risk assessment of India. Earthquake Spectra, 36(S1): 345-371, 2020.

[2] F. Freddi, V. Novelli, R. Gentile, E. Veliu, A. Andonov, S. Andreev, F. Greco, E. Zhuleku, Observations from the $26^{\text {th }}$ November 2019 Albania Earthquake: the Earthquake Engineering Field Investigation Team (EEFIT) mission. Bulletin of Earthquake Engineering, 19(5), 2013-2044, 2020.

[3] T.T. Soong, B.F. Spencer, Supplemental energy dissipation: State-of-the-art and state-ofthe-practice, Engineering Structures, 24, 243-259, 2002. 
[4] L.A. Fahnestock, R. Sause, J.M. Ricles, L.-W. Lu, Ductility demands on buckling-restrained braced frames under earthquake loading, Earthquake Engineering and Engineering Vibration, 2, 255-268, 2003.

[5] F.M. Mazzolani, G. Della Corte, M. D'Aniello, Experimental analysis of steel dissipative bracing systems for seismic upgrading, Journal of Civil Engineering and Management, 15, 7-19, 2009.

[6] L. Di Sarno, G. Manfredi, Experimental tests on full-scale RC unretrofitted frame and retrofitted with buckling-restrained braces. Earthquake Engineering and Structural Dynamics, 41(2), 315-333, 2012.

[7] E.M. Güneyisi, Seismic reliability of steel moment resisting framed buildings retrofitted with buckling restrained braces, Earthquake Engineering and Structural Dynamics, 41 (5), 853-874, 2012.

[8] F. Freddi, E. Tubaldi, L. Ragni, A. Dall'Asta, Probabilistic performance assessment of low-ductility reinforced concrete frames retrofitted with dissipative braces. Earthquake Engineering and Structural Dynamics, 42(7), 993-1011, 2013.

[9] G. Della Corte, M. D'Aniello, R. Landolfo, Field testing of all-steel buckling-restrained braces applied to a damaged reinforced concrete building. Journal of Structural Engineering (United States), 141(1), D4014004, 2015.

[10] F. Freddi, E. Tubaldi, A. Zona, A. Dall'Asta, Seismic performance of dual systems coupling moment-resisting frames and buckling-restrained braced frames. Earthquake Engineering and Structural Dynamics, 50(2), 329-353, 2021.

[11] A. Zona, A. Dall'Asta. Elastoplastic model for steel buckling-restrained braces. Journal of Constructional Steel Research, 68(1), 118-125, 2012.

[12] E. Tubaldi, M. Barbato, A. Dall'Asta, Influence of model parameter uncertainty on seismic transverse response and vulnerability of steel-concrete composite bridges with dual load path. Journal of Structural Engineering, 138(3), 363-374, 2012.

[13] A. Dall'Asta, F. Scozzese, L. Ragni, E. Tubaldi, Effect of the damper property variability on the seismic reliability of linear systems equipped with viscous dampers. Bulletin of Earthquake Engineering, 15(11), 5025-5053, 2017.

[14] F. Scozzese, A. Dall'Asta, E. Tubaldi, Seismic risk sensitivity of structures equipped with anti-seismic de-vices with uncertain properties. Structural Safety, 77, 30-47, 2019.

[15] N. Kotoky, F. Freddi, J. Ghosh, M. Raghunandan, BRBs uncertainty propagation in seismic retrofit of RC structures. $13^{\text {th }}$ International Conference on Applications of Statistics and Probability in Civil Engineering (ICASP13), Seoul, South Korea, 26-30 May 2019.

[16] F. Freddi, J. Ghosh, N. Kotoky, M. Raghunandan, Device Uncertainty Propagation in Low-Ductility RC Frames Retrofitted with BRBs for Seismic Risk Mitigation. Earthquake Engineering \& Structural Dynamics, 2021. DOI: 10.1002/eqe.3456

[17] EN 15129. Anti-seismic devices. European Committee for Standardization 2018; Brussels, Belgium.

[18] ASCE/SEI 7-16. Minimum design loads and associated criteria for buildings and other structures. American Society of Civil Engineers 2016, Reston, VA. 
[19] ASCE 41-13. Seismic Evaluation and Retrofit Rehabilitation of Existing Buildings. American Society of Civil Engineers 2013, Reston, VA.

[20] J.M. Bracci, A.M. Reinhorn, J.B. Mander, Seismic resistance of reinforced concrete frame structures designed for gravity loads: performance of structural system. ACI Structural Journal, 92(5), 597-608, 1995.

[21] L.E. Aycardi, J.B. Mander, A.M. Reinhorn, Seismic resistance of reinforced concrete frame structures designed only for gravity loads: experimental performance of subassemblages. ACI Structural Journal, 91(5), 552-563, 1994.

[22] ACI Committee 318. Building code requirements for reinforced concrete and commentary (ACI 318-89/ACI 318R-89). American Concrete Institute, Detroit, 1989.

[23] McKenna F, Fenves GL, Scott MH. Open system for earthquake engineering simulation. University of California 2006, Berkeley, CA.

[24] M.H. Scott, G.L. Fenves, Plastic hinge integration methods for force-based beam-column elements. Journal of Structural Engineering, 132(2), 244-252, 2006.

[25] T.B. Panagiotakos, M.N. Fardis, Deformation of reinforced concrete members at yielding and ultimate. ACI Structural Journal, 98(2), 135-148, 2001.

[26] J.S. Jeon, L.N. Lowes, R. DesRoches, I. Brilakis. Fragility curves for non-ductile reinforced concrete frames that exhibit different component response mechanisms. Engineering Structures, 85, 127-143, 2015.

[27] F. Freddi, J.E. Padgett, A. Dall'Asta, Probabilistic seismic demand modeling of local level response parameters of an RC frame. Bulletin of Earthquake Engineering, 15, 1-23, 2017.

[28] J.W. Baker, N. Jayaram, S. Shahi, New ground motion selection procedures and selected motions for the PEER transportation research program. PEER Technical Report 2011/03, Berkeley, CA, 2011.

[29] G.E.P. Box, K.B. Wilson, On the Experimental Attainment of Optimum Conditions, Journal of the Royal Statistical Society. Series B (Methodological), 13(1), 1-45, 1951.

[30] T.W. Simpson, J.D. Poplinski, P.N. Koch, J.K. Allen, Metamodels for computer-based engineering design: survey and recommendations, Engineering with computers, 17(2), 129-150, 2001.

[31] D.W. Hosmer, L. Stanley, R.X. Sturdivant, Applied logistic regression. Wiley, Hoboken, N.J., 2013.

[32] P.S. Koutsourelakis, Assessing structural vulnerability against earthquakes using multidimensional fragility surfaces: A Bayesian framework. Probabilistic Engineering Mechanics, 25(1), 49-60, 2010. 